\title{
ARQUEOLOGIA PESSOAL: DESCOBRIR A SUA DIVERSIDADE INTERIOR ATRAVÉS DE ARTEFACTOS DA INFÂNCIA
}

LUÍS MANUEL PINTO

https://orcid.org/0000-0002-8825-8342

Learning for Well-being Foundation

LINDA O'TOOLE

https://orcid.org/0000-0002-4785-1473

Learning for Well-being Foundation

RESUMO Este artigo descreve uma autoexploração do principal autor através de artefactos da sua própria infância, na tentativa de "dar voz" às características estruturantes na criança que foi, e se mantiveram no adulto que hoje é. Esse relato pessoal e íntimo surge da colaboração dos autores no desenvolvimento da "Arqueologia Pessoal", um exercício para pais e profissionais da infância baseado no trabalho da Fundação Learning for Well-being, que vê os indivíduos como sistemas inteiros. No centro dessa abordagem, destacam-se os princípios dos sistemas vivos e o reconhecimento da "diversidade interior" formas fundamentais de capturar e integrar experiências que organizamos individualmente para criar uma representação do mundo externo que nos é idiossincrática. 0 artigo inclui diretrizes para que o leitor possa explorar sua própria Arqueologia Pessoal através de artefactos - fotografias, objetos, desenhos, textos - e histórias que indiquem narrativas pessoais, atitudes e padrões de funcionamento que perduram ao longo do tempo. Concluímos com uma reflexão sobre o valor de exercícios de autoexploração biográfica e a importância da questão da diversidade interior no bem-estar e participação de crianças e adultos.

Palavras-chave: Bem-estar. Diversidade interior. Artefactos. Autobiografia. Criança Interior.

\section{ABSTRACT PERSONAL ARCHEOLOGY: DISCOVERING YOUR INNER DIVERSITY THROUGH CHILDHOOD ARTIFACTS}

This article describes a self-exploration by the primary author through artifacts from his own childhood, in an attempt to "give voice" to the qualities present in the child he was, and in the adult he is today. This 
personal and intimate account springs from the collaboration of the authors on a personal archeology exercise developed for parents and childhood professionals and based on the work of the Learning for Well-being Foundation, which views individuals as whole systems. At the heart of this approach is an emphasis on the principles of living systems and the recognition of "inner diversity" -- fundamental ways of capturing and integrating information that we organize individually to create a representation of the external world that is uniquely our own. The article includes guidelines for the reader to engage in their own personal archeology--searching for artifacts (e.g. photographs, objects, drawings, texts) and stories which indicate personal narratives, attitudes and functioning patterns that last over time. We conclude with a reflection on the value of biographical self-exploration exercises and the importance of the issue of inner diversity in the well-being of children and adults.

Keywords: Well-being. Inner diversity. Self-reflection. Artifacts. Autobiography. Inner child.

\section{ARQUEOLOGÍA PERSONAL: DESCUBRIENDO SU DIVERSIDAD INTERIOR A TRAVÉS DE LOS ARTEFACTOS DE LA INFANCIA}

Este artículo describe una autoexploración del autor principal a través de artefactos de su propia infancia, en un intento de "dar voz" a las características estructurantes del niño que fue y permaneció en el adulto que es hoy. Este relato personal e íntimo surge de la colaboración de los autores en el desarrollo de "Arqueología Personal", un ejercicio para padres, madres y profesionales de la infancia basado en el trabajo de la Fundación Aprendizaje para el Bienestar (Learning for Well-being), que ve a los individuos como sistemas integrales. En el corazón de este enfoque están los principios de los sistemas vivos y el reconocimiento de la "diversidad interior", formas fundamentales de captar y integrar experiencias que organizamos individualmente para crear una representación del mundo externo que nos e idiosincrásica. El artículo incluye pautas para que el lector explore su propia arqueología personal, buscando artefactos (por ejemplo, fotografias, objetos, dibujos, textos) e historias que indiquen narrativas personales, actitudes y patrones de funcionamiento que perduran en el tiempo. Concluimos con una reflexión sobre el valor de los ejercicios de autoexploración biográfica y la importancia del tema de la diversidad interior en el bienestar y participación de niños y adultos.

Palabras clave: Bienestar. Diversidad interior. Artefactos. Autobiografía. Niño interior. 


\section{Introducão}

Há um fio que se segue. Faz parte

das coisas que mudam. Mas não mudam.

[...]

Nunca soltamos o fio.

"The Way It Is", um poema de William Stafford (1999)

Começamos este artigo examinando duas ideias que fundamentam a perspetiva da fundação "Aprender para o Bem-estar"1 sobre as crianças ${ }^{2}$ como seres plenos. Em primeiro lugar, os princípios que regem todos os sistemas vivos - living systems perspective - oferecem uma lente através da qual podemos entender as crianças como pessoas plenas. Em segundo lugar, reconhecer a diversidade interior como forma de respeitar a voz única de cada criança, dentro do paradigma de como elas processam informação e dão sentido às suas experiências. Com base nesses entendimentos, descrevemos um exercício intitulado "Arqueologia Pessoal", que foi desenhado para apoiar explorações individuais de diversidade interior em adultos por meio de reflexão pessoal e biográfica. Incluiremos diretrizes que permitirão ao leitor conduzir sua própria Arqueologia Pessoal através de entrevistas estruturadas com familiares e recolha de artefactos da sua infância. Ilustraremos o exercício com exemplos pessoais de um dos autores deste artigo, mostrando como essa forma de reflexão pode extrair informações importantes sobre características que permanecem constantes ao longo da vida; e como essas informações podem ser fundamentais para enquadrar a perceção de si e as suas interações com o mundo. 0 artigo conclui considerando o potencial da reflexão autobiográfica, através de exercícios como

1 Learning for Well-being Foundation. Para mais informações consultar o website da fundação: https:// www.learningforwellbeing.org.

2 Consideramos "criança" qualquer pessoa com idade inferior a 18 anos de idade, como definido pela Convenção Universal dos Direitos Humanos. a Arqueologia Pessoal, para apoiar o entendimento das vozes das crianças e enriquecer o seu relacionamento com adultos de referência nas suas vidas, sejam pais, educadores ou investigadores na área da infância.

\section{Entender as crianças como sistemas inteiros}

A fundação Aprender para o Bem-estar iniciou suas atividades em 2004, com a intenção de mudar paradigmas sobre as crianças, o bem -estar e a aprendizagem. Um novo paradigma apresentado pela fundação postula uma visão das crianças com agência, em vez de objetos de cuidado; do bem-estar como integral, em vez da simples ausência de doença, e da aprendizagem como diferenciada e holística, em vez de uniforme e focada apenas no desenvolvimento cognitivo (KICKBUSCH; GORDON; O'TOOLE, 2012).

Inspirada da natureza, a abordagem Aprender para o Bem-estar aplica os princípios intrínsecos aos sistemas vivos à maneira como vemos as crianças, e o seu desenvolvimento ao longo da vida. Como contexto deste artigo, destacamos quatro desses princípios e a razão pela qual os consideramos importantes na maneira como vemos e tratamos as crianças. Todos os sistemas vivos, do microscópico ao gigante: (1) auto-organizam-se constantemente em direção ao equilíbrio; (2) são compostos de uma estrutura fractal; (3) são guiados por um impulso central; e (4) são singulares na sua expressão.

Auto-organização: os sistemas vivos estão em constante movimento dinâmico em direção ao equilíbrio e à saúde. Eles auto-organizamse, através de padrões únicos de funcionamento que constituem a sua maneira de responder e integrar a sua interação com o ambiente. Reconhecer a auto-organização nas crianças implica vê-las como seres com agência e assumir 
que as suas escolhas e comportamentos têm a função, até certo ponto, de criar significado nas suas vidas. Reconhecer o princípio de auto-organização é também um convite a adotar uma visão orientada ao processo, em vez de ao resultado, sobre o comportamento das crianças. Podemos descrever como leões caçam as suas presas, ou como uma flor liberta pólen, sem considerar o quão brutal o leão é, ou como o pólen agrava alergias. Com a mesma atitude, podemos observar e ouvir as crianças de uma maneira não julgadora, não patológica e sem ter por base uma noção de deficit que busca entender como a criança funciona, em vez de se funciona ou não funciona.

Impulso centralizador: existe um impulso centralizador em cada sistema vivo. Trata-se de um elemento que o ajuda a encontrar o significado e propósito da sua existência. Nas células, tal informação está localizada nas mitocôndrias. Nos seres humanos, essa parte central poderá não ter um lócus físico, mas usando essa metáfora biológica, podemos afirmar que são organismos orientados para a constante busca de sentido e propósito (GEISEN, 2013; MATURANA; VARELA, 1987). Essa procura representa uma condição para o bem-estar humano (SELIGMAN, 2002) e, por vezes, também sobrevivência (LEACH, 2018). Reconhecer um impulso centralizador nas crianças é vê-las como "almas em evolução" (RANADE, 2006) entendendo que uma dimensão essencial de si procura sentido e propósito, e que estes thes permite florescer e realizar seu potencial único no mundo.

Estrutura fractal: "Um dos aspetos mais marcantes da estrutura fractal [nos sistemas vivos] é que seus padrões característicos são encontrados repetidamente em escalas descendentes, de modo que as suas partes, em qualquer escala, tenham um formato semelhante ao todo" (IRWIN, 2004). Podemos ver repetidos aspetos essenciais de um ser vivo ao longo de sua vida, mesmo quando ele cresce e muda de forma. Elementos de uma flor podem ser identificados nas suas sementes e rebentos, assim como a forma de uma espécie animal está, na essência, representada tanto na sua expressão adulta como nas suas crias. Se reconhecermos a estrutura fractal dos seres humanos, podemos considerar que algumas características essenciais das crianças, físicas e psicológicas, se repetem e mantêm uma certa integridade ao longo da vida.

Singularidade: o quarto princípio é transversal a todos os três princípios descritos anteriormente. Todos os seres são expressões individualizadas de vida. Os seus padrões de auto-organização são únicos, assim como a sua estrutura e o que os guia nas suas buscas de sentido. Reconhecer a singularidade de cada criança é um convite para que os adultos de referência sejam guiados pela curiosidade e que se abstenham de fazer generalizações adultistas (BELL, 1995) baseadas na própria experiência pessoal enquanto criança, ou em imagens construídas de infância que estão presentes nas nossa narrativas sociais (SORIN; GALLOWAY, 2006).

\section{Reconhecer a diversidade interior}

As nossas ações são uma projeção dos nossos mundos interiores. Existem muitas dimensões que poderíamos considerar quando falamos de "mundos interiores". Certamente, a esfera afetiva, incluindo sentimentos e relacionamentos, seria uma na qual o exercício de Arqueologia Pessoal descrito neste artigo poderia ser aplicado de forma útil. No entanto, a perspetiva que enfatizamos neste artigo é a que é descrita pela abordagem Aprender para o Bem-estar como "diversidade interior", e como essa se relaciona com os princípios regentes dos sistemas vivos naturais destacados na primeira seção deste artigo. 
Resumidamente, a diversidade interior afirma que cada criança tem seus próprios padrões únicos de auto-organização, e esses refletem a sua expressão como pessoa (sistema) inteira(o) (O'TOOLE, 2013). Esses padrões são formas fundamentais de capturar e integrar informações que organizamos internamente para representar o mundo externo. Muitos desses padrões guardam uma certa integridade ao longo da vida, como uma estrutura fractal. A diversidade interior é frequentemente sentida em termos de padrões de processamento, tanto de perceção como de expressão, e pode ser observada em diferenças individuais na forma de aprender, de comunicar e de tomar decisões. Referimo-nos a essas diferenças "como fazemos" - a maneira pela qual nos comportamos ou expressamos - em contraste com "o que fazemos" - as ações ou assuntos específicos.

Geralmente, podemos encontrar um espelho entre as qualidades internas de um indivíduo e o produto das suas criações. Um exemplo: Alfred Kinsey era um entomologista americano que durante uma importante parte da sua carreira catalogou e estudou vespas antes de se tornar amplamente conhecido por mudar nossa compreensão da sexualidade humana. No filme biográfico O Relatório Kinsey (CONDON, 2004), vemos como os eventos da sua vida de casal despertaram uma curiosidade que o levou a estudar o comportamento sexual humano. Desde então e até ao momento da sua morte, Kinsey havia conduzido 17 mil entrevistas pessoais com um grupo diversificado de pessoas sobre as suas experiências sexuais. Ele aplicou a mesma sede de compreensão e a mesma postura sistemática, metódica e sem julgamento para os seres humanos, como a que usava anteriormente para os insetos. Enquanto o objeto do seu interesse mudou drasticamente - de vespas para humanos - a forma como ele exprimiu e seguiu o seu interesse manteve muitas semelhanças.

No contexto da diversidade interior, os padrões de processamento aos quais nos referimos são em grande parte inatos. Eles desdobram-se, adaptam-se e tornam-se mais flexíveis, mas mantêm uma certa coerência ao longo da vida. Eles são afetados, mas não fundamentalmente alterados, por outras dimensões de socialização como a identidade de gênero, educação, ambiente social ou cultural (Figura 1).

Figura 1 - Modelo iceberg e representação da diversidade interior

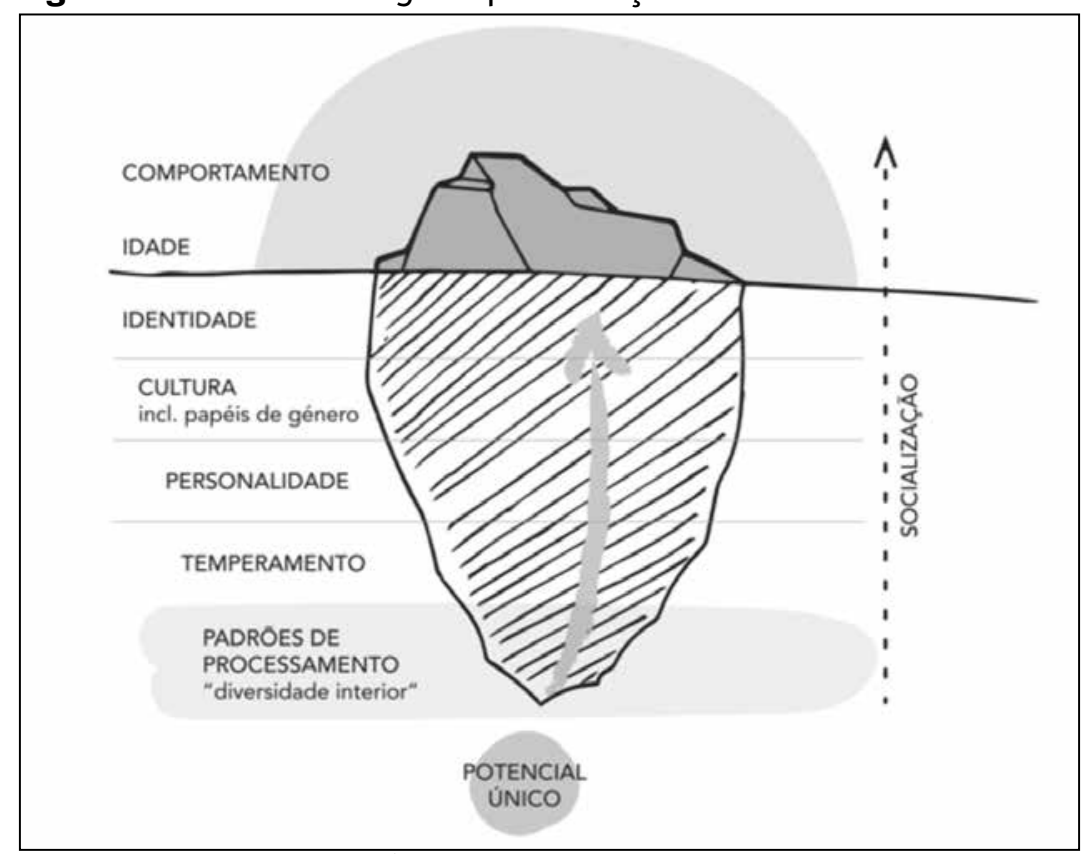

Fonte: Luís Manuel Pinto / Learning for Well-being Foundation. 
Mantendo uma consistência ao longo do tempo e um foco objetivo nos esquemas de funcionamento, esses padrões parecem agir naturalmente como uma fonte de vitalidade e bem-estar. Descobrir e operar a partir desse lugar natural pode ser descrito como "sentir-se casa". Compreender e reconhecer expressões únicas de diversidade interior nas crianças é, portanto, uma condição crítica, e muitas vezes desconsiderada, para reconhecer as crianças como seres plenos, dotados de um potencial único. É igualmente importante considerar a diversidade interior ao ouvir os relatos de crianças sobre suas próprias vidas, porque os adultos - sejam profissionais de educação, pais, investigadores etc. - têm o seu próprio sistema operativo através do qual filtram e frequentemente julgam as informações recebidas de outras pessoas, incluindo crianças. Frequentemente, interpretam mal ou distorcem o que é dito com base nos seus próprios padrões internos.

Existem inúmeros padrões que podemos considerar, alguns dos quais serão examinados nas secções posteriores. No trabalho sobre diversidade interior da fundação Aprender para o Bem-estar, frequentemente comparamos episódios comuns na vida das crianças através dos quais podemos refletir sobre diferenças individuais em relação à forma como se organizam internamente. Essas podem ser vistas em situações comparáveis longo da vida - a primeira infância, a vida escolar, os relacionamentos, o trabalho -, em crianças e adultos, e tornam-se especialmente evidentes quando comparamos uma criança (ou adulto) a outra. A seguir, identificamos alguns padrões que são relativamente fáceis de observar, oferecendo uma pergunta central para cada um:

- Ritmo \& tempo - Qual é a sua relação com o tempo e o ritmo? O ritmo e o tempo são mais do que apenas a rapidez, mas geralmente são percebidos primeiro como se sente a rapidez de reação e ação... a sua e a dos outros.

- Atenção - Onde está centrada a atenção? Existe um foco concentrado num único ponto ou a atenção está amplamente dispersa para que se tenha uma visão geral?

- Indagação - Que tipos de perguntas são feitas e quando? Servem para procurar fatos, propósito, conexões ou verifica afirmar a sua compreensão?

- Início - Como inicía uma atividade, especialmente se pela primeira vez? O que é necessário para que se sinta pronta a iniciar um novo processo ou atividade?

- Expressão - Como expressa pensamentos e sentimentos, e através de que modalidade (por exemplo, palavras, gestos, metáforas)? Existe um fluxo contínuo de comentários gerais ou uma consideração mais seletiva, compartilhada com alguma precisão?

É importante que façamos uma distinção em relação aos elementos antes referidos como expressão de uma perspetiva orientada ao processo ${ }^{3}$ (MARTIN; JEAN-SIGUR; SCHMIDT, 2005; ZHAO et al., 2000), em vez de uma perspetiva que procura estabelecer e prever traços ou estruturas de personalidade. A diversidade interior pode ser considerada uma dimensão da personalidade, no sentido em que faz parte do que torna um indivíduo único, mantém determinada consistência ao longo do tempo e tem uma infinidade de expressões (isto é, padrões de pensamento, comportamento, relacionamentos). Não tem o intuito de criar etiquetas de identidade, mas sugere o uso de linguagem descritiva. Por exemplo, falar da "necessidade de interagir com pessoas" em vez de dizer "extrovertido", "prefere trabalhar individualmente" em vez de "distante", "requer um quadro ou estrutura prévia antes de agir"

3 Em inglês: Process-oriented approach 
ao invés de "rígido". Acreditamos que a linguagem neutra e orientada ao processo abre a autodescoberta e o diálogo, enquanto uma linguagem orientada a determinar traços de personalidade costuma apresentar crianças através de visões redutoras e, por vezes, prejudiciais (O'TOOLE, 2008).

\section{O exercício de Arqueologia Pessoal}

$\mathrm{Na}$ nossa pesquisa com diversidade interior na primeira infância, percebemos que os padrões de processamento poderiam ser identificados muito cedo através da observação do relacionamento das crianças com o ritmo/ tempo, a atenção, a indagação, o início de atividade, e a expressão. Às vezes, as pistas eram sutis, mas, como uma semente, continham qualidades essenciais de padrões mais complexos que viriam a desenvolver enquanto as crianças observadas cresciam. Por exemplo, sabemos que os pais reconhecem que os seus filhos, em comparação um com o outro, geralmente variam na rapidez e no ritmo dos seus movimentos, fala, vontade de se envolver com uma atividade e assim por diante. Se colocarmos duas crianças num contínuo de ritmo e rapidez, do mais sustentado ${ }^{4}$ ao mais rápido, podemos constatar uma predominância para cada criança em particular, especialmente percetível quando começa novas atividades. Podemos perguntar: quanto tempo precisa uma criança para que se sinta pronta a iniciar e concluir uma tarefa? Quanto tempo de aviso precisa uma criança para que se sinta pronta a deixar um ambiente ou atividade específicos? As crianças nas quais observamos um ritmo mais rápido quando bebés - por exemplo, no seu movimento ou vontade de mudar de atividade - tendem mais tarde a ser as primei-

4 Preferimos não utilizar a palavra "lento" pela sua conotação pejorativa ligada à incapacidade cognitiva. ras crianças numa sala de aula a responder a perguntas, e talvez também ser conhecidas mais tarde como adultos de "gatilho rápido" que iniciam projetos sem considerar todas as informações. Da mesma forma, os bebés que apresentam um ritmo mais estável ou sustentado, provavelmente têm uma trajetória consistente: geralmente respondem na sala de aula apenas quando têm o contexto completo - o que requer mais tempo - e levam esse padrão em particular para a sua vida adulta. É importante entender essas observações como correlações, e não como previsões.

Como queríamos ajudar pais a captar essas diferenças intrínsecas e sutis, demos instruções a um grupo de adultos com quem trabalhávamos para filmar os seus próprios filhos - com idades entre dois e quatro anos -, e selecionámos um conjunto de perguntas para orientar as suas observações e reflexões. Ao recebermos as respostas dos pais, vimos uma relação entre a sua capacidade de perceber os seus próprios padrões de funcionamento, e a capacidade de reconhecer os padrões de funcionamento nos seus filhos. Pareceu-nos, então, importante cultivar a consciência dos pais para que essa se traduzisse no bem-estar dos seus filhos, permitindo-lhe a expressão plena da sua diversidade interior sem que os seus próprios filtros sejam impostos.

Também assumimos que, se os padrões observados nas crianças mantinham um certo grau de integridade ao longo do tempo, seria possível, no sentido inverso, explorar com os pais das mesmas crianças os padrões que permaneceram constantes nas suas próprias vidas desde a sua infância. Quisemos que as suas autorreflexões biográficas fossem apoiadas em aportes outros que as suas próprias memórias de infância, por isso adaptámos as perguntas originais a entrevistas semiestruturadas que os pais poderiam usar com seus respetivos pais -avós das crianças - ou com ou- 
tras pessoas de referência que testemunharam o seu crescimento. Esse caminho fez-se sentir como uma "escavação do passado", à descoberta de tesouros nas narrativas pessoais que possam ajudar a revelar partes importantes de si mesmos, e que de outro modo não estariam cientes. A esse exercício chamámos "Arqueologia Pessoal".

Além da entrevista estruturada, incentivámos os pais a recolher fotografias e artefactos, como textos ou desenhos desde a infância. Também considerámos as histórias contadas pelos familiares como representativas das idiossincrasias dos pais - enquanto crianças - ou frases que os pais repetiam durante a infância.

\section{Conduzir sua própria Arqueologia Pessoal}

Aqui, estão as diretrizes que demos aos pais sobre como conduzir sua própria Arqueologia Pessoal:

\section{Arqueologia Pessoal sobre diversidade in- terior}

O objetivo do exercício de Arqueologia Pessoal é orientar uma autorreflexão exploratória, baseada em entrevistas e em artefactos de infância. Queremos identificar padrões de "diversidade interior" - forma de funcionar que foram consistentes ao longo do tempo, ver como evoluíram e como se expressaram de forma diferente em diferentes idades.

As entrevistas podem ser feitas com qualquer pessoa de referência na sua vida que o(a) tenha observado crescer desde o nascimento - ou tenra idade - e possa espelhar alguns dos seus próprios comportamentos.

Artefactos da infância são quaisquer objetos que fornecem informações sobre seu comportamento, interesses ou atitudes na infância. Podem ser simplesmente fotografias ou gravações em vídeo, objetos que criou como obras de arte, ou textos ou outros documentos, como relatórios escolares, cartas, etc.

O que procurar ...

- Procure a lógica natural e interna na maneira como abordou as coisas desde a infância. Sobretudo se esses momentos ou artefactos teriam sido vividos ou realizados sem esforço, e sentiu que eles traziam vitalidade, em vez de esgotá-lo;

- Procure padrões críticos que tenham permanecido de certo modo constantes na maneira como você se relaciona com tempo e ritmo; como, e a que, prestou atenção; como iniciou uma atividade - especialmente uma nova atividade; como, e o que, compartilhou com outras pessoas e como registou mudanças e progresso;

- Descreva padrões usando uma linguagem orientada ao processo. Isso significa ter uma postura sem julgamento, sem patologia e sem deficit. Procure descrever o que realmente fazia, não o que achava, ou outra pessoa achou, que deveria estar fazendo;

- Reflita se esses padrões encontram uma expressão na idade adulta, como eles possam ter evoluído e se expressado em diferentes idades, e até que ponto estes padrões o definem ou mudam seu sentimento de si e sua relação com o mundo.

Lidando com as perceções de outras pessoas sobre si:

- Esteja preparado para a possibilidade de que as respostas a essas perguntas possam surgir como julgamentos de caráter, por exemplo: "eras muito teimoso enquanto bebé". o importante é que tente extrair o que a situação significava para si - quando criança - a 
partir da perspetiva do adulto, e depois refletir como o episódio se traduz em padrões específicos de comunicação e processamento de informação. Nesses casos, é útil pedir exemplos específicos do que foi rotulado como "teimoso" (ou qualquer que seja o julgamento);

- Da mesma forma, quando as respostas às perguntas surgem como elogios, como "eras uma criança especial" ou "eras muito organizado", procure exemplos específicos que possam ajudá-lo a entender o que isso significava sobre como se organizava internamente, em vez dos seus traços de caráter.

\section{Protocolo de entrevista}

Antes do nascimento: pergunte sobre a experiência da sua mãe do seu ritmo antes de nascer. Muitas mães falam sobre como bebês diferentes têm ritmos muito diferentes no útero. A sua mãe notou essas diferenças?

Primeiros três meses: quais foram meus ritmos de dormir, comer, chorar? Quão ativamente respondi a estímulos externos?

Idade de um a três anos:

- Quais eram minhas características marcantes?

- Em que parecia ter facilidade?

- Em que parecia sentir-me desafiado?

- Se tinha tarefas a fazer, como as abordava?

Idade de três anos ou mais:

- Quais eram minhas formas preferidas de jogar / passar o tempo? Pode falar sobre algo que parecia gostar muito de fazer?

- Como eu interagia com um objeto - por exemplo: um brinquedo?

- Como eu interagia com outra pessoa por exemplo: uma criança da mesma idade?
- Como me comportava num grupo de pessoas focadas numa situação - por exemplo: um filme, um espetáculo de marionetes ou um animal?

- Como me movia no espaço? Movia-me muito ou ficava num só lugar? Moviame diretamente de um ponto para outro, de forma mais errática?

- Como lidava com o final de uma atividade e o início de outra? Por exemplo precisava ser alertado de que o tempo estava terminado? Gostava de brincar ou trabalhar em muitas coisas ao mesmo tempo, ou terminava uma atividade antes de começar outra?

- Quais foram as coisas que pareciam importantes para mim ou das quais gostava muito?

- Quais eram as coisas que as pessoas diziam constantemente sobre minha maneira de ser? Ou seja, outros familiares, amigos ou professores.

- Que tipo de situação realmente me incomodaria?

- O que chamaria minha atenção? Sob que circunstâncias?

- Quais foram as circunstâncias nas quais eu perderia o interesse numa atividade, objeto ou pessoa?

\section{Um exemplo de Arqueologia Pessoal}

São duas as razões pelas quais decidimos partilhar resultados selecionados de uma das arqueologias pessoais dos autores. Primeiro, queríamos ilustrar concretamente a natureza do material que pode ser descoberto através do exercício e mostrar, por exemplo, como tais informações podem contribuir para o bem -estar e desenvolvimento pessoal. Segundo, queríamos modelar uma atitude em relação à investigação, na qual a visão subjetiva do 
investigador é considerada um valor, e não um obstáculo na produção de conhecimento (MIZZI, 2010).

Os exemplos seguintes pertencem ao autor Luís Pinto, a partir da sua própria exploração autobiográfica usando o exercício de Arqueologia Pessoal. Os artefactos de infância referidos incluem uma entrevista com sua mãe sobre sua infância antes dos dez anos, (utilizando as perguntas antes mencionadas); duas fotos do autor num contexto semelhante em momentos distintos, uma aos cinco e outra aos 24 anos; um poema escrito pelo autor ao seu padrinho com idade entre oito e dez anos. 0 autor continua a próxima seção na primeira pessoa para enfatizar a natureza pessoal dos exemplos mostrados.

Descrevo a seguir os padrões que pude encontrar, ilustrando-os através de histórias e artefactos selecionados. Também mostrarei onde a minha reflexão confirmou, matizou ou contradisse as imagens que mantive de mim próprio.

\section{Padrão 1: impulso para completar e melhorar sistemas humanos}

Esta história contada por minha mãe sobre mim aos sete ou oito anos, ilustra um padrão que considero fundamental na forma como aprendo e me relaciono com as pessoas e o mundo.

Lembro-me da tua professora da 2a classe dizer que costumavas fazer muitas perguntas, e um dia perguntaste 'como nascem os bebés'. Acho que ela respondeu algo que não te satisfez, porque ficou surpresa ao ver que no dia seguinte trouxeste para a escola um livro sobre o corpo humano e acabaste a explicar-lhe [à professora] como os bebés eram criados e nascidos. (Mãe do autor, 2012)

Lembro-me desse impulso de querer compreender como as coisas funcionam, especial- mente como as pessoas funcionam, enquanto sistemas, e ser levado a refletir e a expressar com frequência como esses sistemas poderiam tornar-se mais eficazes. A Figura 2 ilustra o mesmo padrão através de um poema escrito durante a escola primária, dirigido ao meu padrinho. O motivo central do poema é um pedido para que ele pare de beber álcool. Os argumentos que dou são "o mal que lhe está a fazer", que ele deveria ouvir-me "porque sou um pouco mais novo", que ele pode "pelo menos tentar", porque "ainda há remédio". Essas mensagens são ao mesmo tempo acompanhadas por expressões de afeto chamando-o de "querido" e dedicando o poema "com todo o meu amor". A forma usada para o poema é uma quadra com um esquema $A B C B$, tradicional na cultura popular portuguesa.

Figura 2 - Poema aos 8-10 anos

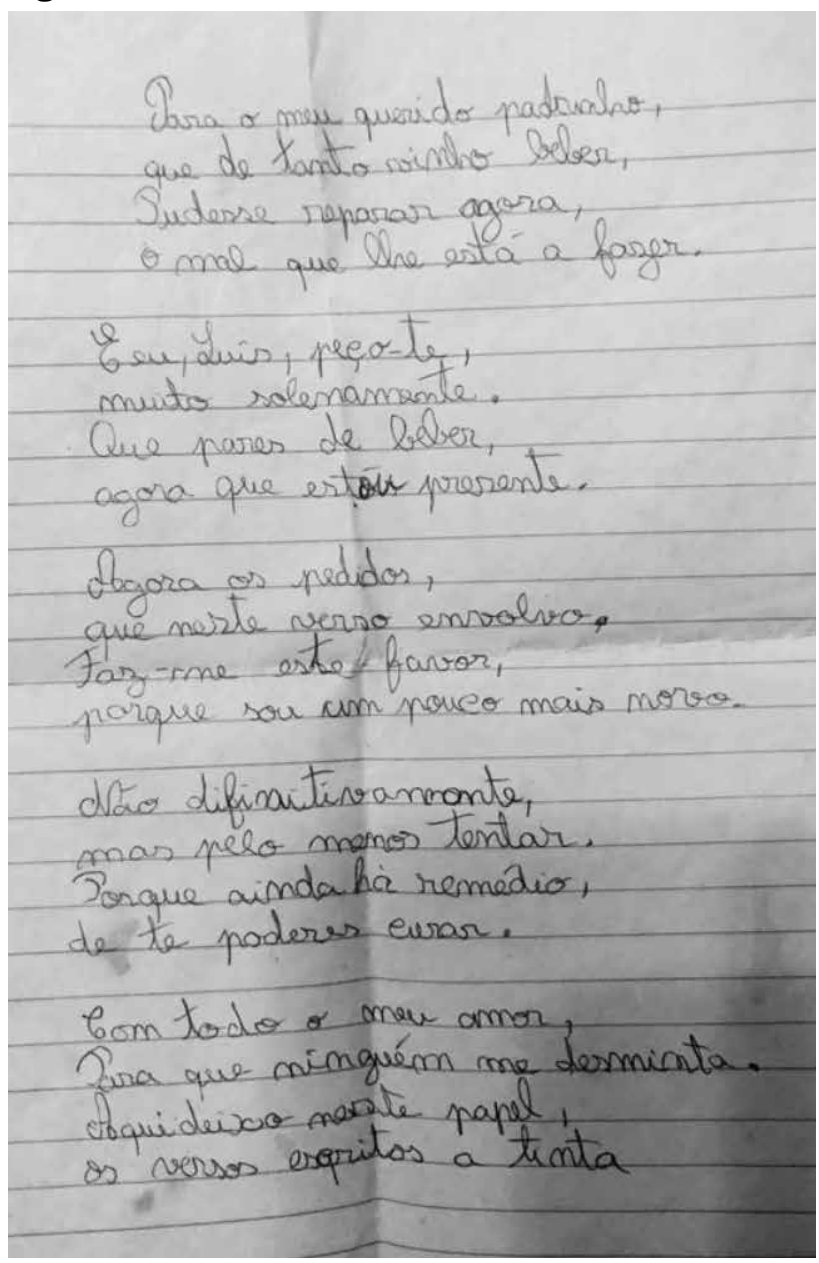

Fonte: Luís Manuel Pinto. 
0 artefacto do poema demonstra tanto o padrão de como presto atenção aos sistemas humanos para torná-los mais completos, neste caso o "sistema humano" trata-se de uma pessoa familiar. Ilustra também um outro padrão relacionado à forma como minha criatividade é estimulada, isto é, começando a partir de, ou em reação a, uma estrutura pré-existente (i.e. quadra ABAC).

Segue outro exemplo do impulso de melhorar sistemas humanos, dessa vez, a partir dos 12 anos, mas aplicado a um grupo ou ambiente social, e não a uma pessoa.

Na escola, fiz o que chamei de 'análise sociológica' da minha turma. Dei um apelido a cada pessoa, classifiquei-as em termos de poder e popularidade e desenhei um diagrama das relações entre cada uma. Dei este 'plano' à minha então professora de inglês para que ela pudesse reorganizar as aulas de maneira que as pessoas menos familiarizadas se sentassem juntas e como consequência se sentissem menos encorajadas a conversar na sala de aula. (Pinto, 2012) $)^{5}$

\section{Padrão 2: adotando um ponto de vista periférico ou interno em ambientes sociais}

As Figuras 3 e 4 representam-me num ambiente de grupo com cinco anos de idade (Figura 3) e 25 anos (Figura 4). 0 que é semelhante nas duas situações é que estou num grupo que teve que seguir uma certa forma no espaço (alinhado, voltado para a mesma direção). Nos dois grupos, estou colocado parte traseira das filas. Nos dois contextos, existe a presença de um facilitador ou professor guiando o grupo na frente do espaço.

0 que se repete, com 20 anos de intervalo, é a maneira como seguro meus braços - o mesmo braço sobre o outro -, a inclinação e o ângulo da minha cabeça, e as qualidades do

5 Notas pessoais do autor feitas no momento do exercício da Arqueologia Pessoal. meu olhar que está pousado num ponto além do grupo e nos limites do espaço. Pude dar-me conta que essa mesma posição foi adotada em muito mais momentos do que os capturados nessas duas fotografias.

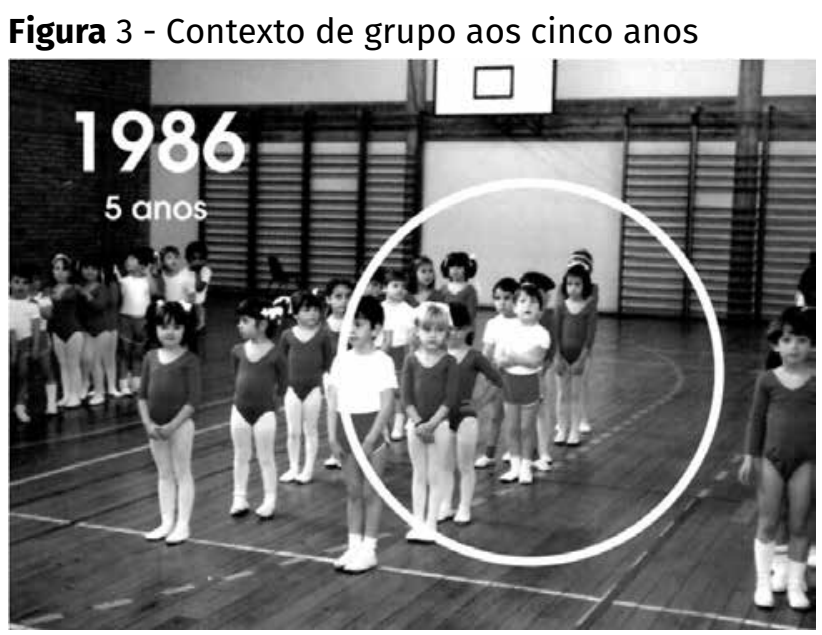

Fonte: Luís Manuel Pinto.

Figura 4 - Contexto de grupo aos 25 anos

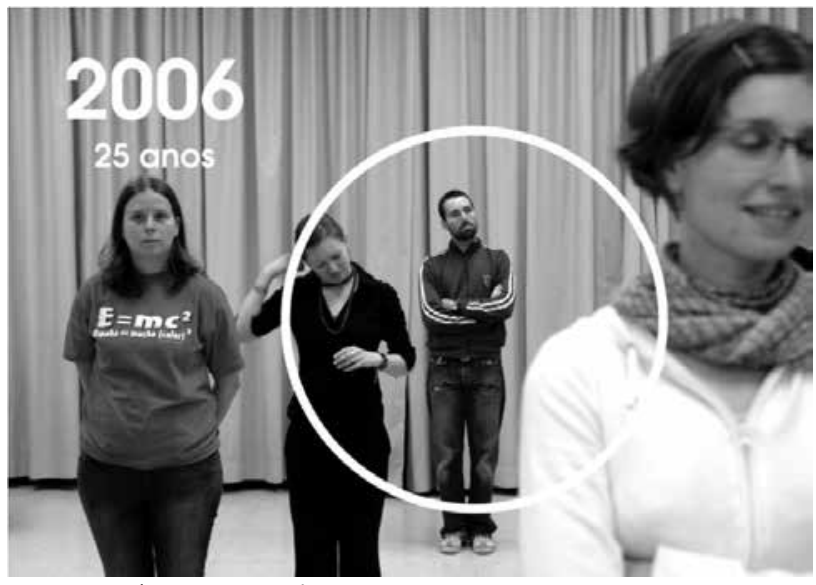

Fonte: Luís Manuel Pinto.

Padrão 3: organização interna antes de expressar ou agir com alta competência

o padrão trazido à minha consciência através das histórias que se seguem está relacionado à quantidade de tempo e reflexão em que um pensamento ou intenção é mantido interiormente antes de ser expresso ou manifesto com um certo grau de detalhe.

Eu pude identificar esse padrão na história sobre como minha mãe descreveu as minhas primeiras palavras: 
Começaste a andar aos 13 meses de idade, antes de começar a falar. Quando começaste a dizer as primeiras palavras, elas eram claramente compreensiveis. (Mãe do autor, 2012)

Essa história despoletou uma imagem de mim enquanto infante na qual cuidadosamente esculpi palavras na minha mente, onde as guardei até ter certeza de que estavam prontas. 0 mesmo padrão também foi expresso na maneira que a minha mãe descreveu a minha organização dos meus espaços físicos pessoais:

Eras organizado e desorganizado... Pedias-me para não tocar nas tuas coisas - mesmo que estivessem desarrumadas - e um dia organizavas tudo de uma só vez. Encontravas o teu caminho na sua própria desarrumação e foste cedo responsável pelas tuas próprias coisas... las sempre além do que te era pedido na escola. (Mãe do autor, 2012)

Reconheço nesse episódio o padrão de acumular complexidade no espaço físico - que era suficientemente confortável para viver - e de levar tempo até que eu sentisse que poderia trazer ordem detalhada ao espaço. Essa história também demonstra aspetos do padrão antes descrito de querer sistemas completos, no fato de sempre adicionar às tarefas que me eram atribuídas na escola.

O principal resultado da minha reflexão pessoal não foi a possibilidade de fazer um inventário das características que se mantiveram no tempo, mas o impacto que essa reflexão teve na minha narrativa pessoal e, consequentemente, na maneira como percebo a infância e outras crianças - especialmente aquelas com os quais me relaciono ou trabalho atualmente.

Compreender e aceitar que, aos sete anos de idade, procurei informações que ajudariam a minha professora a responder à pergunta de como os bebés nascem, ou que, alguns anos depois, escrevia um poema ao meu padrinho sobre como ele se beneficiaria com o deixar de beber álcool matizou a forma como eu até então entendia os meus motivos. Se eu afastar de mim o rótulo de tais atos como expressões de arrogância ou "de saber melhor que outros", posso começar a reconhecer que os episódios lembrados apontam para um padrão de funcionamento interno que é essencial para o modo como me relaciono com a vida. Posso encontrar exemplos do mesmo padrão noutras idades, inclusive na semana passada, e encontrar uma sensação de aceitação e um ânimo pela possibilidade de poder descrever esse padrão de uma forma positiva para mim e para os outros.

Do mesma modo, perceber que demoro um pouco num estado de complexidade e que preciso ter uma compreensão profunda de um assunto, ou sistema, como um todo, antes que uma ação ou resposta se forme, ajudou-me a entender que não era uma questão de "levar uma eternidade a agir" ou ser um "procrastinador", mas que era a maneira do meu sistema responder ao meu ambiente e, de fato, de me permitir trazer esta forma natural de funcionar como uma qualidade a todas as situações - eu posso sentir a autoaceitação necessária para fazer o melhor trabalho possivel com tempo e contexto suficientes.

Embora essas reflexões altamente subjetivas criem uma sensação de empoderamento e reconciliação com aspetos essenciais que me definem, elas não significam o fim de uma jornada nem reivindicam um determinado território em torno do qual construo barricadas expressas como "é assim que eu sou". É pelo contrário, o começo de uma jornada, ou a autodescoberta contínua da adaptação eterna aos ambientes e relacionamentos em minha volta, mas com um capital de autoestima e conhecimento de si sólidos.

\section{Considerações para} relacionamentos, prática e
pesquisa

Um dos maiores desafios relacionados ao 
cumprimento do direito da criança a ser ouvida e levada a sério - como estipulado na Assembleia Geral das Nações Unidas, em 1989 - é a capacidade do adulto de atribuir significado e legitimidade ao que as crianças expressam. Isso geralmente significa um preconceito do adulto ao responder à questão de "quando uma criança é capaz de formular suas próprias opiniões" (LLOYD; EMERSON, 2017), mas acreditamos que outro obstáculo menos discutido possa ser o preconceito sobre a diferentes modalidades de expressão adotadas por crianças que acabam por ser consideradas irrelevantes ou inutilizáveis. Quanto mais jovens as crianças, maior o preconceito sobre suas capacidades e a forma como elas se expressam. Considerar a diversidade interior significa expandir o universo daquilo que consideramos digno de significado. Usar uma orientação ao processo para entender não apenas o que a criança está expressando, mas como a criança está expressando, é uma atitude de respeito pela criança como pessoa plena.

0 reconhecimento da diversidade interior também tem implicações importantes no bem -estar e na participação das crianças. À medida que crescemos e desenvolvemos, o mesmo acontece com os nossos padrões internos de funcionamento. Num desenvolvimento positivo ao longo da vida, tais padrões tornam-se mais flexiveis e integrados, e o nosso leque de respostas possiveis aumenta, mas mantém-se uma sensação de "regresso a casa" quando temos espaço para utilizar os padrões que sentimos como naturais, ou sem esforço (O'TOOLE; GORDON, 2015). A experiência de bem-estar de cada criança é, portanto, única. Uma criança pode precisar de mais estrutura, enquanto outra mais flexibilidade. Uma criança pode precisar de maior interação social, enquanto outra precisa de tempo sozinha. A pesquisa sobre o bem-estar das crianças deve levar em consideração as visões subjetivas das crianças so- bre como elas vivem o próprio bem-estar (BEN -ARIEH, 2019). Como grupo social, as crianças vivem e descrevem o bem-estar de uma maneira diferente da dos adultos, mas uma compreensão aprofundada do bem-estar de cada criança exige a ampliação do campo de investigação para a compreensão dos padrões de diversidade interior que constituem uma fonte de vitalidade e motivação para cada criança.

Entender a participação das crianças através das lentes da diversidade interior, convida os pais, os profissionais de cuidados infantis e investigadores a relaxar as suas expectativas de como uma criança deve expressar seus pontos de vista (O'TOOLE, 2019). As expectativas e as imagens projetadas por adultos nas respostas das crianças podem levar a considerar o seu conteúdo ou a forma de expressar as suas opiniões como insuficientes ou inadequadas. Frequentemente, os adultos esperam apenas alguns segundos antes de oferecer palavras ou instruções para incentivar ou orientar a resposta da criança, às vezes, nem percebendo como interferem ao procurar ajudar ou acelerar o processo. Tais reações podem resultar na perturbação, desconsideração ou distorção das perspetivas da criança. Recordar o princípio da auto-organização ajuda-nos a ser guiados pela indagação e o uso de linguagem neutra para descrever como a criança participa, e não se está ou não participando. Essa é uma abordagem baseada nas forças e valores da criança (LOPEZ; LOUIS, 2009) que cultiva um ambiente que permite que as crianças partiIhem e expressem seus pontos de vista de forma autêntica, seja num contexto familiar, educacional ou de pesquisa.

Finalmente, sugerimos que o reconhecimento de padrões de diversidade interior ao longo da vida como forças naturais pode ser significativo no desenvolvimento pessoal e profissional do adulto. Revisitar as suas memórias de infância através das lentes de diver- 
sidade interior, pode ajudar os adultos a recuperar o "território" da sua infância, indagando, observando e empatizando com os padrões de processamento interno que terão sido constantes nas suas narrativas pessoais, descobrindo assim os valores neles inerentes. Essa exploração pode transformar uma narrativa pessoal de incompreensão ou desafio, numa de resiliência e valor (INGAMELLS; EPSTON, 2012; WHITE, 1988). A pesquisa educacional demonstrou que a prática da autorreflexão biográfica pode contribuir para o desenvolvimento profissional dos professores (KOSTER; VAN DEN BERG, 2014). O que apoiamos neste artigo é que a análise de padrões de diversidade interior, por meio de exercícios como a Arqueologia Pessoal, pode ser integrada não apenas na formação de professores, mas também na prática autorreflexiva de qualquer adulto que se relacione com crianças.

O caminho que descrevemos não é necessariamente fácil de seguir, mas esperamos ter demonstrado que se trata de uma exploração interessante, proveitosa e útil a muitos níveis. Ela mantém a promessa de ver e ser visto, em todos os nossos aspetos, como o ser único que cada um de nós é.

\section{Referências}

ASSEMBLEIA GERAL DAS NAÇÕES UNIDAS. Convenção sobre os Direitos da Criança. 1989.

BELL, John. Understanding Adultism: A major obstacle to developing positive youth-adult relationships. United States. YouthBuild USA, p. 1-7, march 1995. Available at: https://actioncivics.scoe.net/pdf/ Understanding_Adultism.pdf. Accessed ont: 10 fev. 2020.

BEN-ARIEH, Asher. The Well-being of the World's Children: lessons from the international survey of children's well-being. Children's Subjective Well-being in Local and International Perspectives. Statistikaamet, p. 18-29, august 2019. Available at: https:// www.stat.ee/publication-2019_childrens- subjective-well-being-in-local-and-international -perspectives. Accessed ont: 10 fev. 2020.

CONDON, Bill. Kinsey. United States: American Zoetrope and Myriad Pictures, 2004.

GEISEN, Guus. Autopoiesis: perspective on sustainable, meaningful education. Netherlands: Netherlands Enterprise Agency, 2013.

INGAMELLS, Kay; EPSTON, David. Placing strengths into storylines: building bridges between strengths-based and narrative approaches. International Journal of Narrative Therapy and Community Work, n. 3, p. 50-61, may 2012. Available at: https://yourstory.org.nz/wp-content/uploads/2019/03/Placing-strengths-into-storylines-Building-bridges-between-strengths-based-and-narrative-approaches -by-Kay-Ingamells-and-David-Epston.pdf. Accessed ont: 10 fev. 2020.

IRWIN, Terry. Extracts : living systems principles and their relevance to design. Devon England: Schumacher College/University of Plymouth, 2004.

KICKBUSCH, Ilona; GORDON, Jean; O'TOOLE, Linda Aprender para o bem-estar: uma prioridade política para crianças e jovens na Europa. Um processo de mudança. Lisboa: Fundação Calouste Gulbenkian, 2012.

KOSTER, Bob; VAN DEN BERG, Bas. Increasing professional self-understanding: self-study research by teachers with the help of biography, core reflection and dialogue. Studying Teacher Education, v. 10, n. 1, p. 86-100, 2014. DOI: 10.1080/17425964.2013.866083

LEACH, John. 'Give-up-itis' revisited: neu ropathology of extremis. Medical Hypotheses. v. 120, p. 14-21, 1 nov. 2018. Available at: https://www.sciencedirect. com/science/article/abs/pii/S0306987718306145. Accessed ont: 10 fev. 2020.

LLOYD, Katrina; EMERSON, Lesley. (Re)examining the Relationship between children's subjective wellbeing and their perceptions of participation rights. Child Indicators Research, v. 10, n. 3, p. 591-608, 2017. Available at: https://link.springer.com/article/10.1007/ s12187-016-9396-9 Accessed ont: 10 fev. 2020.

LOPEZ, Shane J.; LOUIS, Michelle C. The Principles of 
Strengths-Based Education. Journal of College and Character, Informa UK Unlimited, v. 10, n. 4, 2009. DOI: 10.2202/1940-1639.1041

MARTIN, David Jerner; JEAN-SIGUR, Raynice; SCHMIDT, Emily. Process-oriented inquiry-A constructivist approach to early childhood science education: Teaching teachers to do science. Journal of Elementary Science Education, Illinois, USA: Kennesaw State University, v.17, n.2, p. 1-22, 2005. DOI: 10.1007/ BF03174678

MATURANA, Humberto. R.; VARELA, Francisco. J. The Tree of Knwoledge: The Biological Roots of Human Understanding. United States: Shambhala Publications, Ine, 1987.

MIZZI, Robert. Unraveling researcher subjectivity through multivocality in autoethnography. Journal of Research Practice, v. 6, n. 1, p. 28-42, 2010. Available at: http://jrp.icaap.org/index.php/jrp/article/ view/201/185 Accessed ont: 10 fev. 2020.

O'TOOLE, Linda. Understanding individual patterns of learning: implications for the well-being of students. European Journal of Education. v. 43, n. 1, p. 71-86, 2008. DOI: $10.1111 / j .1465-3435.2007 .00335 . x$

O'TOOLE, Linda. Well-being as Wholeness The Perspective, Process, and Practice of Learning for Well -being. In: MATTHES, Michiel et al. (ed.). Improving the quality of childhood in Europe 2013, Brussels: Quality of Childhood Europe, v. 5, 2013. p. 22-35.

O'TOOLE, Linda. Inner Differences: Exploring how we seek to know. Learning for well-being magazine. Amsterdam: Learning for Well-being Foundation, 2019.

O'TOOLE, Linda; GORDON, Jean. Can we measure happy, healthy and meaningful lives? Learning for well-being magazine. 2015.

RANADE, Shraddhalu. Introduction to integral education: an inspirational guide. Pondicherry: Sri Aurobindo International Institute for Educational Research, 2006.

SELIGMAN, Martin. E. P. Authentic Happiness: using the new positive psychology to realize your potential for deep fulfilment. New York: Free Press, 2002.

SORIN, Reesa; GALLOWAY, Greta. Constructions of childhood: constructions of self. Children Australia, v. 31, n. 2, p. 12-21, 2006. Available at: https://www. cambridge.org/core/journals/children-australia/ article/constructs-of-childhood-constructs-ofself/D72200BBCCD52FA554A02BD525CC8087 Accessed ont: 10 fev. 2020.

STAFFORD, William. The way it is. Revised Edition. Minneapolis: Graywolf Press, 1999.

WHITE, Michael. The externalizing of the problem and the re-authoring of lives and relationships. In: WHITE, M. Selected Papers. Adelaide: Dulwich Centre Publications. 1988. p. 5-28.

ZHAO, Hongxin et. alli. Studying the real child rather than the ideal child: Bringing the person into developmental studies. In: BERGMAN, Lars R.; CAIRNS, Robert B.; LARS-GORAN, Nilsson; NYSTEDT, Lars (ed.). Developmental science and the holistic approach. Psychology Press, 2000. p. 393-4319.

Recebido em: 03/05/2020 Revisado em: 05/08/2020 Aprovado em: 18/08/2020

Luís Manuel Pinto é mestre em Ciências da Educação pela Vrije Universiteit Brussel. Diretor de Programas e Aprendizagem da Fundação Learning for Well-Being, com sede em Amsterdão (Holanda). E-mail: luismanuelpinto@gmail.com

Linda 0'Toole é Senior Fellow da Fundação Learning for Well-being. Está particularmente interessada nos padrões pelos quais as pessoas se envolvem e processam suas experiências internas e externas. E-mail: lotoole1@earthlink.net 